\title{
Results of staged repair of aortic disease in patients with Marfan syndrome
}

Yuki Ikeno, MD, Koki Yokawa, MD, Hidekazu Nakai, MD, Katsuhiro Yamanaka, MD, PhD, Takeshi Inoue, MD, Hiroshi Tanaka, MD, PhD, and Yutaka Okita, MD, PhD

\section{ABSTRACT}

Objective: We present our open surgical strategies for staged replacement of the thoracic and thoracoabdominal aorta in patients with Marfan syndrome.

Methods: Between October 1999 and December 2017, 82 patients with Marfan syndrome underwent 118 aortic repairs. We divided the aorta into 4 segments for categorization: (1) the aortic root, (2) aortic arch, (3) descending thoracic, and (4) abdominal aorta. Procedures were categorized according to the types of surgery. Staged repair was defined as a subsequent operation on a different segment of the aorta after initial repair $(n=111,94.1 \%)$, and reoperation was defined as an operation on the same segment $(\mathrm{n}=7,5.9 \%)$.

Results: The mean age at initial operation was $41.7 \pm 14.9$ years. Staged repairs included aortic root replacement $(n=42,36 \%)$, total arch replacement $(n=11$, $9.3 \%)$, combined aortic root and total arch replacement $(\mathrm{n}=13,11 \%)$, descending aorta replacement $(\mathrm{n}=4,3.4 \%)$, thoracoabdominal aortic repair $(\mathrm{n}=36$, $31 \%$ ), and extensive arch-descending or thoracoabdominal repair $(\mathrm{n}=5$, $4.2 \%$ ). Four patients received 3 staged repairs. Operative mortality was $0.8 \%$ $(1 / 118)$. Stroke occurred in $1.7 \%(2 / 118)$, and spinal cord injury occurred in $1.7 \%$ (2/117). Overall survival was $95.8 \pm 2.4 \%$ at 10 -years. Twenty-four patients underwent replacement of the whole aorta after $2.5 \pm 3.8$ years following initial repair.

Conclusions: Our strategies for staged replacement of the thoracic and thoracoabdominal aorta in patients with Marfan syndrome resulted in excellent early- and long-term outcomes. (J Thorac Cardiovasc Surg 2019;157:2138-47)

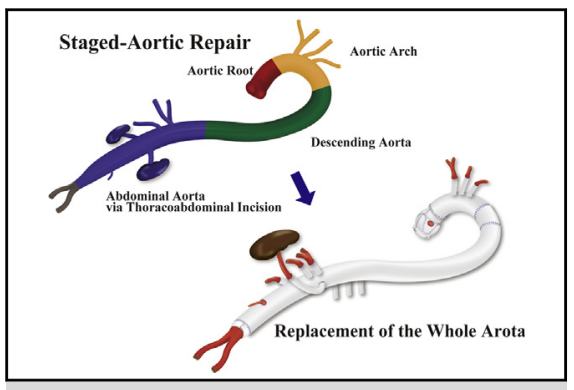

Schema of replacement of the whole segment of the aorta.

\section{Central Message}

Open surgical strategies for staged replacement of thoracic and thoracoabdominal aorta achieve excellent outcomes in patients with Marfan syndrome.

\section{Perspective}

The strategies of staged replacement of thoracic and thoracoabdominal aorta provide better outcomes in the treatment of aortic disease in Marfan syndrome.

See Commentary on page 2148.
Marfan syndrome (MFS) is an autosomal-dominant, connective tissue disorder that affects the cardiovascular, skeletal, and ocular systems. The life expectancy of patients with MFS was previously estimated to be 32 years ${ }^{1}$ but has improved with developments in surgical techniques used to manage complications such as acute aortic dissection and aortic rupture. 2,3

Replacement of the whole aorta (RWA) is considered the goal of treatment for aortic disease in patients with MFS. It is common for these patients to have multiple, staged aortic operations throughout their lifetime. A staged approached to "complete aortic replacement" (from the aortic root/ ascending aorta to the infra-renal abdominal aorta/aortic bifurcation) in MFS, or other connective tissue disorders, has been used and previously reported, ${ }^{3,4}$ although the utility of each study is limited because of the small number of patients requiring this procedure. Endovascular therapies also have shown promise for the successful management of aortic pathologies in patients with MFS; however, long-term outcomes of these techniques remain unclear. $^{5}$
From the Department of Cardiovascular Surgery, Kobe University, Kobe, Japan. Received for publication May 11, 2018; revisions received Aug 11, 2018; accepted for publication Aug 24, 2018; available ahead of print Oct 26, 2018.

Address for reprints: Yutaka Okita, MD, PhD, Division of Cardiovascular Surgery,

Department of Surgery, Kobe University Graduate School of Medicine, 7-5-2

Kusunoki-cho Chuo-ku, Kobe 650-0017, Japan (E-mail: yutakaokita@ gmail.com). 0022-5223/\$36.00

Copyright (c) 2018 by The American Association for Thoracic Surgery

https://doi.org/10.1016/j.jtcvs.2018.08.109

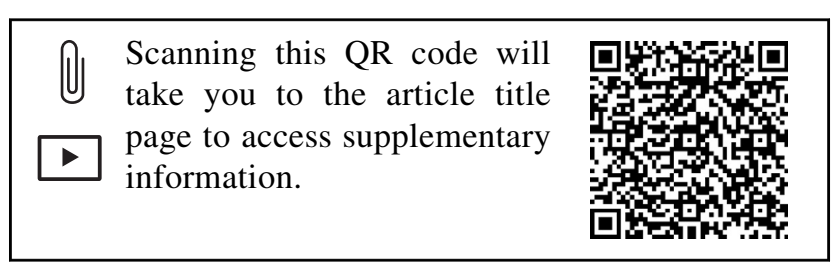




\section{Abbreviations and Acronyms}

$\mathrm{AAAD}=$ acute type $\mathrm{A}$ aortic dissection

$\mathrm{AAE}=$ annuloaortic ectasia

$\mathrm{CPB}=$ cardiopulmonary bypass

ICA $=$ intercostal artery

MFS = Marfan syndrome

RWA = replacement of the whole aorta

TAAA $=$ thoracoabdominal aortic aneurysm

In short, there is still a great deal of controversy in this field regarding the extent of staged operations and surgical indications for replacement of residual aorta, particularly in patients without aortic dissection. ${ }^{6}$ The purpose of this study was to evaluate our open surgical strategies with staged replacement of the thoracic and thoracoabdominal aorta in patients with MFS.

\section{METHODS}

\section{Patients}

Between October 1999 and December 2017, 82 patients with MFS (defined using current Ghent criteria ${ }^{7}$ ) underwent 118 thoracic aortic repairs at our institution. The mean age at the initial operation was $41.7 \pm 14.9$ years. Twenty-eight of 82 patients underwent 38 aortic repairs ( 27 procedures via median sternotomy, 9 procedures via thoracotomy, and 2 via endovascular repair) before those performed at our hospital (Table E1). The mean follow-up duration after initial staged aortic surgery was $7.1 \pm 4.7$ years. Follow-up data were obtained by clinical visit, telephone, or written correspondence. The follow-up rate was $95.1 \%$, with 4 patients being lost to follow-up within 1 year. The ethics committee of our hospital approved this study. The required informed consent was waived. The study protocol was reviewed and approved by the institutional review board.

\section{Definitions}

We divided the aorta into 4 segments: (1) the aortic root, (2) aortic arch, (3) descending thoracic aorta, and (4) abdominal aorta via thoracoabdominal incision (Figure 1). Staged repair was defined as an initial aortic operation followed by a subsequent operation on a different segment of the aorta. Reoperation was defined as an operation on the same segment. RWA was achieved when prosthetic grafts had replaced all 4 segments (Figure 2).

The operative mortality was defined as all 30-day mortality and inhospital mortality, including any occurring after transfer to another hospital or long-term acute care facility. Overall survival and aortic events were measured as the time from the first staged operation performed at our institution. Aortic events included as aortic reoperation, aortic dissection, aortic aneurysm rupture, and death. Vascular surgery without cardiopulmonary bypass (CPB), such as abdominal aortic aneurysm repair, common iliac artery aneurysm repair, subclavian artery aneurysm repair, and common femoral artery aneurysm repair, also were included in aortic events.

\section{Surgical Strategies}

Aortic lesions in patients with MFS were classified into 4 categories: (1) annuloaortic ectasia (AAE) with or without chronic dissection; (2) acute type A aortic dissection (AAAD); (3) descending thoracic or thoracoabdominal aortic aneurysm (TAAA); or (4) extensive aneurysm from the aortic arch to the descending or thoracoabdominal aorta for distal residual chronic dissection or mega aorta syndrome.

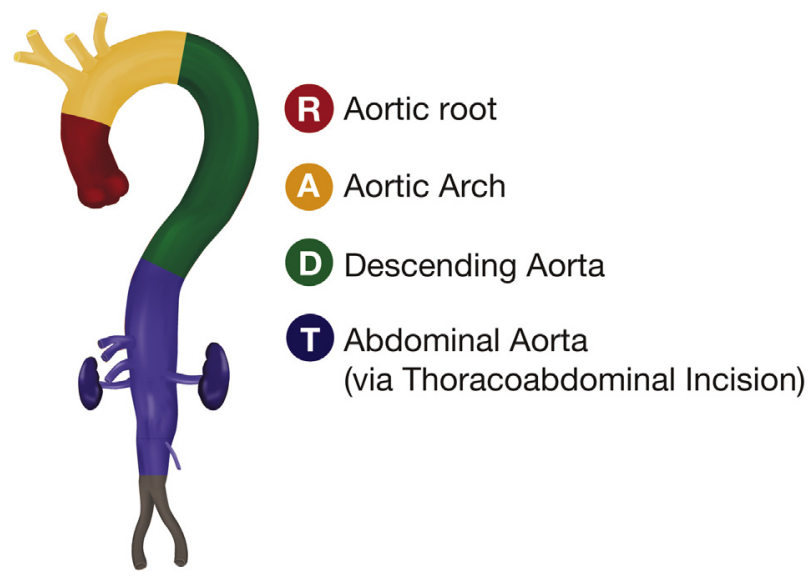

FIGURE 1. The concept of aortic segments; R: aortic root (red), A: aortic arch (yellow), D: descending aorta (green), and T: thoracoabdominal aorta (blue).

We anticipated 2 aortic repairs over the lifetime of a patient with MFS: one via median sternotomy and an additional operation via left thoracotomy. We avoided repeat sternotomy or thoracotomy for patients with a previous aortic operation.

\section{Annuloaortic Ectasia}

Valve-sparing reimplantation was indicated for patients with AAE, given that the cusps could be repaired. Details for this procedure were previously reported by our team ${ }^{8}$ (Video 1 ). The surgical indication for AAE is a Valsalva sinus diameter of $>45 \mathrm{~mm}$. However, valve-sparing root replacement is indicated in patients with dissection of the Valsalva sinus as well as for young, fertile women with a Valsalva sinus diameter $>40 \mathrm{~mm}$. If patients had distal residual chronic dissection, concomitant total arch replacement and elephant trunk installation were performed to provide staged TAAA repair.

\section{Acute Type A Aortic Dissection}

AAAD is life-threatening; thus, emergent surgery was indicated for these patients. The principal aim of our surgical strategy was to excise the primary entry tear. For patients presenting with a DeBakey type I aortic dissection, concomitant root replacement, total arch replacement, and elephant trunk installations were performed regardless of the location of aortic tear, given hemodynamics stability. In the case of hemodynamic instability or malperfusion, the extent of aortic repair was determined by both the location of aortic tear and diameter of aortic root $(\geq 45 \mathrm{~mm})$.

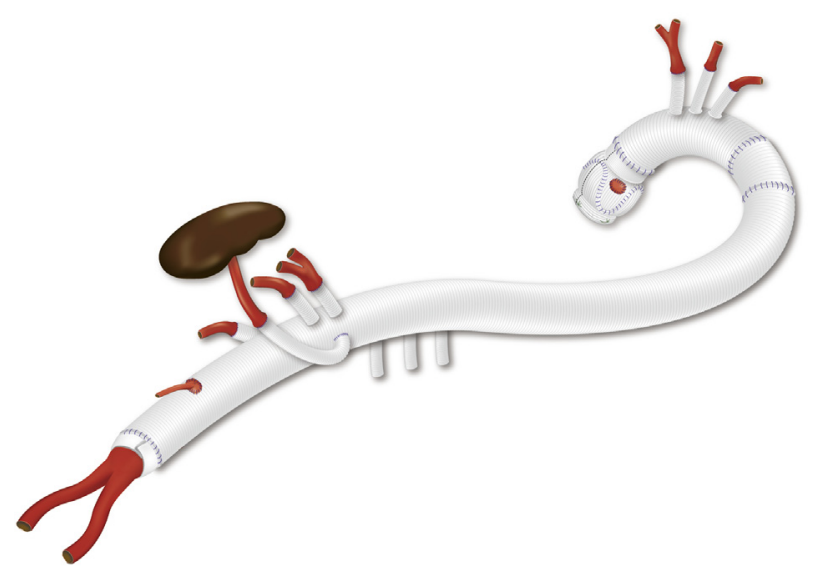

FIGURE 2. Replacement of the whole aorta. 


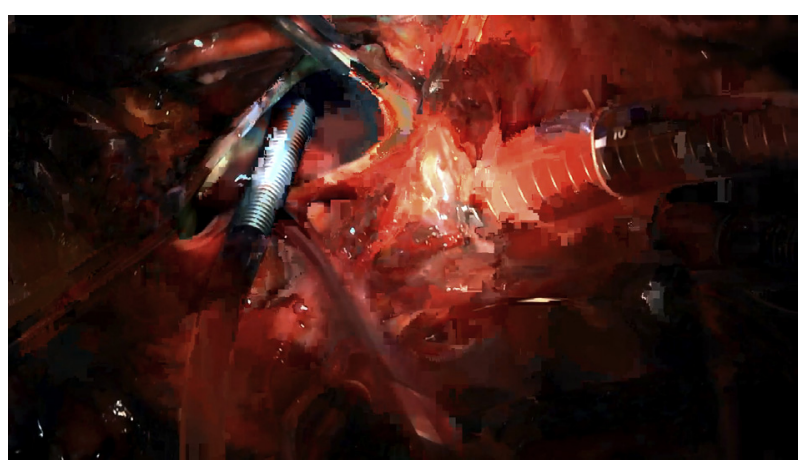

VIDEO 1. The patient underwent total arch-thoracoabdominal aortic repair via left thoracotomy as a first-stage operation, and valve-sparing root replacement reimplantation (VSRR) via median sternotomy as a second-stage operation (reaching replacement of the whole aorta). The patient experienced reoperation for cuff aneurysm of intercostal artery and visceral branch. VSRR: Under cardiac arrest, the replacement of the aortic root was performed using a Valsalva graft (Terumo Medical, Somerset, NJ) with 12 reinforced 3-0 polyester mattress sutures in the first row and continuous 5-0 polypropylene sutures in the second row. In the patient, a fenestration of left coronary cusp was reinforced using polytetrafluoroethylene suture. After confirming the competency of the aortic cusp, implantation of coronary arteries and distal anastomosis was completed. Video available at: https://www.jtcvs.org/article/S0022-5223(18)32504-2/fulltext.

DeBakey type II aortic dissection or thrombosed false lumen were considered indications for limited extension of the aortic arch. Details of the surgical technique for total arch replacement have been previously reported. $^{9}$

Excluding 2 patients, arch vessels were reconstructed individually. A valve-sparing reimplantation technique for aortic root replacement was used for all but 1 patient, who required a salvage operation.

\section{Descending Thoracic or Thoracoabdominal Aortic Aneurysm}

For patients with a dissected TAAA, we used a one-stage graft replacement of the thoracoabdominal aorta. Partial CPB was established by cannulation of the left femoral artery for arterial inflow and the right femoral vein/pulmonary artery for drainage. Details of the indications and surgical techniques using partial CPB have been previously reported. ${ }^{10}$ Our indications for repair included an aortic diameter of $>50 \mathrm{~mm}$ and a rapidly expanding aneurysm (an increase of $>5 \mathrm{~mm}$ in 6 months). Extensive graft replacement for the dissected aneurysm involved reconstruction of the entire thoracoabdominal aorta and all visceral branches, including portions of the aorta that were not yet indicated for repair.

Intercostal arteries (ICAs) and lumbar arteries were reattached by graft interposition $(\mathrm{n}=31)$ or by the island technique $(\mathrm{n}=7)$. Visceral branches were reconstructed individually except for in 2 patients. In patents with infrarenal abdominal aortic aneurysms/dissection or common iliac arterial aneurysms/dissection $(\mathrm{n}=36)$, distal anastomoses were extended beyond the lesion (iliac artery [ $\mathrm{n}=17]$, aortic bifurcation $[\mathrm{n}=11]$, and infrarenal abdominal aorta $[\mathrm{n}=8])$. For patients with ruptured aneurysm $(\mathrm{n}=2)$, nondissecting aneurysm $(n=1)$, and localized dissection $(n=1)$, graft replacement of the descending aorta was indicated.

\section{Extensive Aneurysm}

Preoperative comorbidities often preclude surgical extension. A staged operation consisting of total arch replacement via median sternotomy, followed by descending aortic replacement or TAAA repair, often is preferred. The order of staged repair was determined by the diameter of each segment. Staged arch repair was indicated for patients who had an aortic diameter $>45 \mathrm{~mm}$ or a rapidly expanding aneurysm (increase of $>5 \mathrm{~mm}$ in 6 months). For patients who satisfied both surgical indications between the ascending and descending aorta, total arch replacement and elephant trunk insertion were given priority to simplify proximal manipulation of the next staged TAAA repair.

In patients with few risk factors, we considered more extensive replacement, ranging from the aortic arch to the descending or infrarenal abdominal aorta. Replacement was approached via thoracotomy through the fourth or fifth intercostal spaces with rib-cross thoracotomy (Video 2), ${ }^{11,12}$ so as to avoid the need for aortic operations requiring repeated sternotomy or thoracotomy.

Patients who underwent total arch replacement via median sternotomy for dilated residual arch aneurysm and previous replacement of other aortic segment were included in this pathology because it was considered as a modification of staged aortic arch repair $(\mathrm{n}=2)$. Our indication of residual

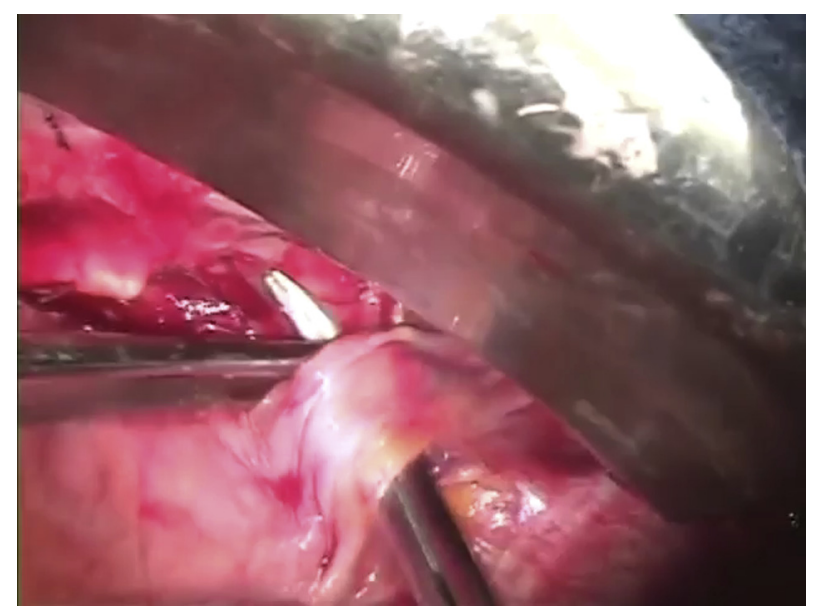

VIDEO 2. The patient underwent total arch-thoracoabdominal aortic repair (TAR-TAAA) via left thoracotomy as a first-stage operation and valve-sparing root replacement reimplantation via median sternotomy as a second-stage operation (reaching replacement of the whole aorta). The patient experienced reoperation for cuff aneurysm of intercostal artery and visceral branch. TAR-TAAA: The patient was set to the right semirecumbent position. After straight long incision from the left subscapular to the left pararectal line, the aortic arch was exposed through the fourth intercostal space with dividing 2 ribs (fifth and sixth) and costal arch. The abdominal aorta was exposed via retroperitoneal approach. The pericardium was opened anterior to the phrenic nerve and the arch was approached over the pulmonary artery. To establish the arterial inflow, the infrarenal abdominal aorta was replaced just above aortic bifurcation under partial heparinization because the patient was so small that usual femoral artery cannulation was not available. The venous drainage was from the pulmonary artery. After full heparinization, segmental aortic replacement was performed in the order of the abdominal aorta (visceral branch using a cuff technique), descending aorta (intercostal artery using a cuff technique), and aortic arch. Aortic arch replacement was performed under moderate hypothermia $\left(<28^{\circ} \mathrm{C}\right.$, rectal temperature) using antegrade cerebral perfusion and an aortic clamping on the mid-part of the descending aortic graft. Cardioplegic solution was administered from the inside of ascending aorta with a balloon-tipped catheter. Perfusion of the heart and brain was re-established after reconstructing ascending aorta and brachiocephalic artery. Video available at: https://www.jtcvs.org/article/ S0022-5223(18)32504-2/fulltext. 
arch repair was an aortic diameter $>45 \mathrm{~mm}$ or a rapidly expanding aneurysm.

\section{Statistical Analysis}

All continuous variables were expressed as the mean \pm standard deviation or as medians and interquartile ranges for non-normal data. The values of actuarial survival and freedom from aortic events were computed using the Kaplan-Meier technique and expressed as the survival rate \pm standard error. Analyses were performed using JMP 11.0 software (SAS Institute, Cary, NC).

\section{RESULTS}

\section{Patient Characteristics}

Patient characteristics for each staged operation are shown in Table 1. Eighty-two patients (mean age $41.1 \pm 14.4$ years old) underwent 118 aortic repairs, including $111(94 \%)$ staged operations (first-stage operation [ $n=82]$, second-stage operation [ $n=25]$, and third or more stage operation $[n=4])$, and $7(5.9 \%)$ reoperations. Aortic repairs were performed for aortic pathologies including AAE $(\mathrm{n}=45,38 \%)$, AAAD $(\mathrm{n}=17,14 \%)$, descending thoracic aorta or TAAA $(\mathrm{n}=40,34 \%)$, and extensive aneurysm $(\mathrm{n}=9,7.6 \%)$. Sixty-four patients underwent 69 aortic repairs via median sternotomy, with 13 repairs involving resternotomy. Forty-four patients underwent 49 aortic repairs via left thoracotomy, with 3 repairs involving rethoracotomy. There were $22(19 \%)$ emergent/urgent aortic repairs included in this study.

\section{Operative Data}

Operative data for each staged operation are summarized in Table 2. The staged surgical procedures included aortic root replacement $(n=42,36 \%)$, total arch replacement $(\mathrm{n}=11,9.3 \%)$, combined aortic root replacement with total arch replacement $(n=13,11 \%)$, descending aorta graft replacement $(n=4)$, TAAA repair $(n=36)$, total arch-descending aorta graft replacement $(\mathrm{n}=2)$, and total arch-TAAA graft replacement $(n=3)$. Forty-nine patients underwent valve-sparing reimplantation for root replacement. Procedural details used for aortic pathology, in each staged operation, are summarized in Tables E2 through E4.

Reoperations included aortic valve replacement due to recurrent $\mathrm{AR}$ after reimplantation (2 patients), graft replacement for graft infection (2 patients; ascending aorta replacement following RWA and descending aorta replacement following TAAA), and ICA cuff aneurysm repair (3 patients).

Mean CPB time was $217.5 \pm 68.9$ minutes, and mean aortic clamp time was $147.6 \pm 63.8$ minutes. Circulatory arrest was performed in 39 patients (33\%). Mean cerebral perfusion time was $73.2 \pm 37.2$ minutes.

\section{Operative Results}

Operative results are shown in Table 3. Operative mortality was $0.8 \%$ ( 1 patient). This patient, who had emergent total arch replacement for AAAD complicated by

TABLE 1. Patient characteristics of whole aortic repairs

\begin{tabular}{|c|c|c|c|c|c|}
\hline Variable & $\begin{array}{c}\text { Whole } \\
(n=118)\end{array}$ & $\begin{array}{l}\text { First stage } \\
(\mathbf{n}=\mathbf{8 2})\end{array}$ & $\begin{array}{l}\text { Second stage } \\
\quad(n=25)\end{array}$ & $\begin{array}{l}\text { Third stage } \\
\quad(n=4)\end{array}$ & $\begin{array}{c}\text { Reoperation } \\
\quad(\mathbf{n}=7)\end{array}$ \\
\hline Age, y & $41.1 \pm 14.4$ & $41.7 \pm 14.9$ & $39.8 \pm 13.8$ & $40.8 \pm 17.9$ & $39.1 \pm 10.7$ \\
\hline Male sex & $60(51)$ & $42(51)$ & $14(56)$ & $1(25)$ & $3(43)$ \\
\hline \multicolumn{6}{|l|}{ Pathologies } \\
\hline Staged operation & $111(94)$ & $82(100)$ & $25(100)$ & $4(100)$ & $0(0)$ \\
\hline Annuloaortic ectasia & $45(38)$ & $39(48)$ & $5(20)$ & $1(25)$ & $0(0)$ \\
\hline Annuloaortic ectasia with distal chronic dissection & $10(9)$ & $10(12)$ & $0(0)$ & $0(0)$ & $0(0)$ \\
\hline Acute type A aortic dissection & $17(14)$ & $14(17)$ & $3(12)$ & $0(0)$ & $0(0)$ \\
\hline Des/TAAA & $40(34)$ & $22(24)$ & $16(64)$ & $2(50)$ & $0(0)$ \\
\hline Dissecting Des/TAAA aneurysm & $38(32)$ & $22(24)$ & $15(60)$ & $2(50)$ & $0(0)$ \\
\hline Nondissection Des/TAAA aneurysm & $2(1.7)$ & $0(0)$ & $2(8.0)$ & $0(0)$ & $0(0)$ \\
\hline Extensive aneurysm & $9(7.6)$ & $7(11)$ & $1(4.0)$ & $1(25)$ & $0(0)$ \\
\hline Reoperation & $7(5.9)$ & $0(0)$ & $0(0)$ & $0(0)$ & $7(100)$ \\
\hline Graft infection & $2(1.7)$ & $0(0)$ & $0(0)$ & $0(0)$ & $2(29)$ \\
\hline Recurrent AR after VSRR & $2(1.7)$ & $0(0)$ & $0(0)$ & $0(0)$ & $2(29)$ \\
\hline ICA patch aneurysm & $3(2.5)$ & $0(0)$ & $0(0)$ & $0(0)$ & $3(43)$ \\
\hline Median sternotomy & $69(59)$ & $56(68)$ & $8(32)$ & $2(50)$ & $3(43)$ \\
\hline Resternotomy & $13(11)$ & $5(6.1)$ & $4(16)$ & $1(25)$ & $2(29)$ \\
\hline Left thoracotomy & $49(42)$ & $26(32)$ & $17(68)$ & $2(50)$ & $4(57)$ \\
\hline Rethoracotomy & $3(2.5)$ & $4(4.9)$ & $2(12)$ & $0(0)$ & $0(0)$ \\
\hline Emergency/urgency & $22(19)$ & $17(21)$ & $2(8.0)$ & $2(50)$ & $1(14)$ \\
\hline
\end{tabular}

Values are mean $\pm \mathrm{SD}$ or $\mathrm{n}(\%)$. Des/TAAA, Descending thoracic or thoracoabdominal aortic aneurysm; $A R$, aortic regurgitation; VSRR, valve-sparing root replacement; ICA, intercostal artery. 
TABLE 2. Operative data

\begin{tabular}{|c|c|c|c|c|c|}
\hline Variable & $\begin{array}{c}\text { Whole } \\
(\mathbf{n}=118)\end{array}$ & $\begin{array}{l}\text { First stage } \\
(\mathbf{n}=\mathbf{8 2})\end{array}$ & $\begin{array}{l}\text { Second stage } \\
\quad(\mathbf{n}=\mathbf{2 5})\end{array}$ & $\begin{array}{l}\text { Third stage } \\
(n=4)\end{array}$ & $\begin{array}{l}\text { Reoperation } \\
\quad(\mathbf{n}=7)\end{array}$ \\
\hline \multicolumn{6}{|l|}{ Surgical procedures } \\
\hline Root replacement & $42(36)$ & $36(44)$ & $5(20)$ & $1(25)$ & $0(0)$ \\
\hline Valve-sparing reimplantation & $38(32)$ & $33(40)$ & $4(16)$ & $1(25)$ & $0(0)$ \\
\hline Total arch replacement & $11(9.3)$ & $7(8.5)$ & $3(12)$ & $1(25)$ & $0(0)$ \\
\hline Root replacement + total arch replacement & $13(11)$ & $13(16)$ & $0(0)$ & $0(0)$ & $0(0)$ \\
\hline Reimplantation + total arch replacement & $11(9.3)$ & $11(13)$ & $0(0)$ & $0(0)$ & $0(0)$ \\
\hline Aortic valve replacement & $2(1.7)$ & $0(0)$ & $0(0)$ & $0(0)$ & $2(29)$ \\
\hline Ascending aorta graft replacement & $1(0.8)$ & $0(0)$ & $0(0)$ & $0(0)$ & $1(14)$ \\
\hline Descending aorta graft replacement & $5(4.2)$ & $1(1.2)$ & $2(8.0)$ & $1(25)$ & $1(14)$ \\
\hline TAAA repair & $36(31)$ & $21(26)$ & $14(56)$ & $1(25)$ & $0(0)$ \\
\hline Extent I & $0(0)$ & $0(0)$ & $0(0)$ & $0(0)$ & $0(0)$ \\
\hline Extent II & $27(23)$ & $16(20)$ & $11(44)$ & $0(0)$ & $0(0)$ \\
\hline Extent III & $8(6.8)$ & $5(6.1)$ & $3(12)$ & $1(25)$ & $0(0)$ \\
\hline Extent IV & $0(0)$ & $0(0)$ & $0(0)$ & $0(0)$ & $0(0)$ \\
\hline Total arch-descending aorta graft replacement & $2(1.7)$ & $1(1.2)$ & $1(4.0)$ & $0(0)$ & $0(0)$ \\
\hline Total arch-TAAA graft replacement & $3(2.5)$ & $3(3.7)$ & $0(0)$ & $0(0)$ & $0(0)$ \\
\hline ICA patch aneurysm repair & $3(2.5)$ & $0(0)$ & $0(0)$ & $0(0)$ & $3(43)$ \\
\hline Cardiopulmonary bypass time, $\min$ & $217.5 \pm 68.9$ & $237.2 \pm 63.6$ & $179.9 \pm 54.5$ & $171.3 \pm 74.0$ & $130.7 \pm 42.3$ \\
\hline Clamp time, min & $147.6 \pm 63.8$ & $152.1 \pm 66.2$ & $131.2 \pm 52.1$ & $146.5 \pm 3.5$ & $99.3 \pm 49.0$ \\
\hline Circulatory arrest & $39(33)$ & $33(40)$ & $5(20)$ & $1(25)$ & $0(0)$ \\
\hline Cerebral perfusion time & $73.2 \pm 37.2$ & $68.1 \pm 32.4$ & $93.0 \pm 52.7$ & 143 & - \\
\hline
\end{tabular}

Values are mean $\pm \mathrm{SD}$ or $\mathrm{n}(\%)$. TAAA, Thoracoabdominal aortic aneurysm; ICA, intercostal artery.

brain and coronary malperfusion, died of low-output syndrome. In terms of postoperative complications $(\mathrm{n}=7$, $5.9 \%)$, stroke occurred in 2 patients $(1.7 \%)$ and spinal cord injury occurred in 2 patients $(1.7 \%)$. The neurologic symptoms of both patients were fully resolved by discharge. Deep wound infection occurred in 1 patient following TAAA repair $(0.8 \%)$. The infection was controlled using continuous irrigation therapy. Tracheostomy was required in 2 patients $(1.7 \%)$.

\section{Sequence of Staged Repair}

The sequence of staged-repair is shown in Figure 3. Stratified by aortic pathologies, initial operation for AAE was indicated in 39 patients (Figure 3, A), AAAD in 14 patients (Figure 3,B), TAAA in 22 patients (Figure 3,C), and extensive aneurysm in 7 patients (Figure 3,D). In our entire cohort of 118 procedures, 1 patient underwent bridging endovascular therapy for a complicated acute type $\mathrm{B}$ dissection (Figure 3, A).

Five of 82 patients died, with 4 of those deaths being late deaths and 1 being an operative mortality. One patient who rejected additional repairs died of residual descending thoracic aortic aneurysm rupture within 10 months of the initial surgery (root reimplantation and total arch replacement). The second patient, who experienced 2 emergent aortic surgeries (total arch replacement for AAAD and graft replacement of descending aorta for aneurysm rupture) and also rejected additional operations, died of residual aneurysm rupture in 11.0 years after initial AAAD repair. The third patient, who underwent total arch replacement for AAAD, descending aorta graft replacement, and extent III TAAA repair for residual lesion, died of pneumonia 3 years after TAAA repair. In addition, 1 patient died of malignancy in 14.7 years after

TABLE 3. Operative results

\begin{tabular}{|c|c|c|c|c|c|}
\hline Variable & $\begin{array}{c}\text { Whole } \\
(n=118)\end{array}$ & $\begin{array}{c}\text { First stage } \\
(\mathbf{n}=\mathbf{8 2})\end{array}$ & $\begin{array}{l}\text { Second stage } \\
\quad(n=25)\end{array}$ & $\begin{array}{l}\text { Third stage } \\
\quad(n=4)\end{array}$ & $\begin{array}{l}\text { Reoperation } \\
\quad(\mathbf{n}=7)\end{array}$ \\
\hline Operative mortality & $1(0.8)$ & $1(1.2)$ & $0(0)$ & $0(0)$ & $0(0)$ \\
\hline Postoperative complications & $7(5.9)$ & $6(7.3)$ & $0(0)$ & $1(25)$ & $0(0)$ \\
\hline Stroke & $2(1.7)$ & $2(2.4)$ & $0(0)$ & $0(0)$ & $0(0)$ \\
\hline Spinal cord injury & $2(1.7)$ & $2(2.4)$ & $0(0)$ & $0(0)$ & $0(0)$ \\
\hline Deep wound infection & $1(0.8)$ & $1(1.2)$ & $0(0)$ & $0(0)$ & $0(0)$ \\
\hline Tracheostomy & $2(1.7)$ & $1(1.2)$ & $0(0)$ & $1(25)$ & $0(0)$ \\
\hline Renal failure & $0(0)$ & $0(0)$ & $0(0)$ & $0(0)$ & $0(0)$ \\
\hline
\end{tabular}

Values are $\mathrm{n}(\%)$. 
Number of staged-repairs
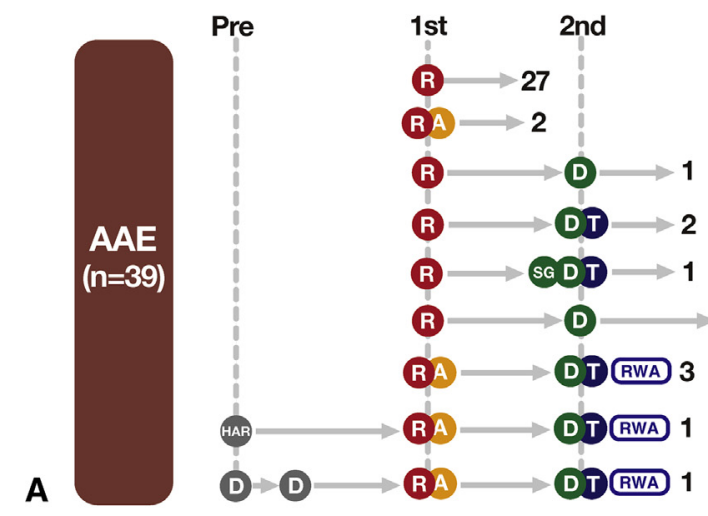

Number of staged-repairs

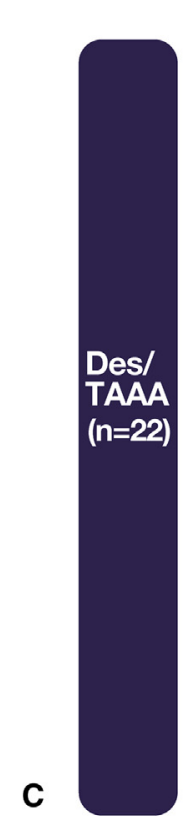

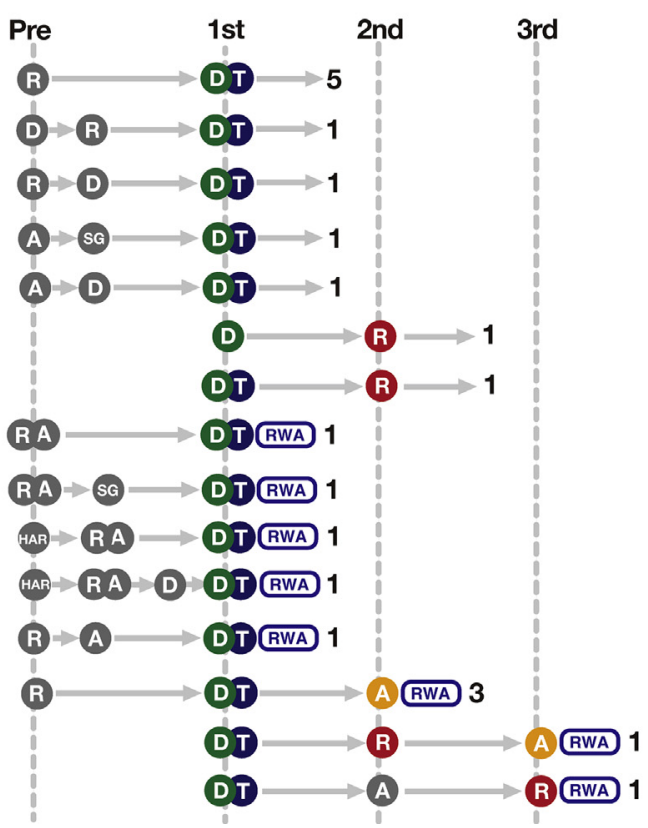

\section{Number of staged-repairs}
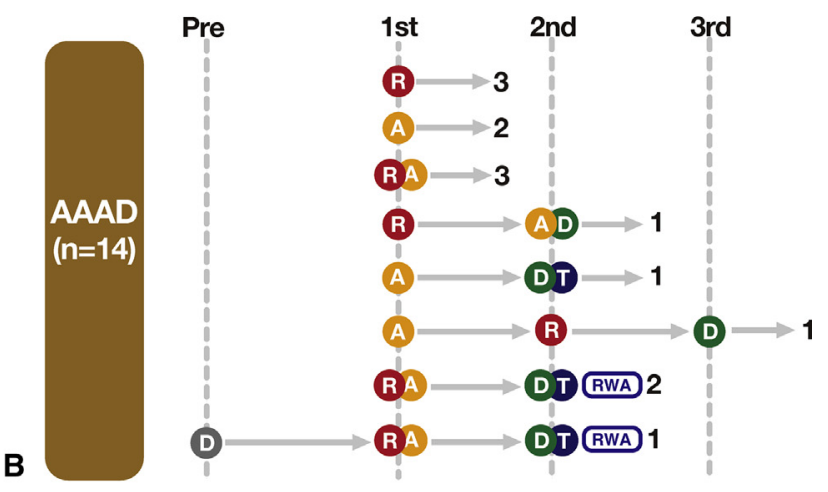

Number of staged-repairs

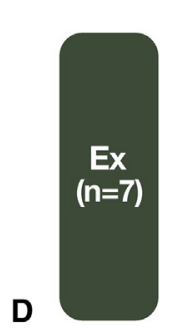

FIGURE 3. Sequence of aortic repair; R (red): root replacement, A (yellow): total arch replacement, D (green): descending aortic replacement, and $\mathrm{T}$ (blue): abdominal aorta via thoracoabdominal incision. Operations that were performed in outside hospitals appear as gray circles. Patients were stratified into 4 groups: (A) initial aortic repair indicated by annuloaortic ectasia $(A A E)$, (B) acute type A aortic dissection $(A A A D)$, (C) descending thoracic or thoracoabdominal aortic aneurysm (Des/TAAA), and (D) extensive aortic aneurysm (Ex). HAR, Hemiarch replacement; $S G$, stent grafting; $R W A$, replacement of the whole aorta.

RWA. Overall survival was $95.8 \pm 2.4 \%$ at 10 years (Figure 4, A).

At our most recent time point, the number of aortic segments replaced was 1 in 32 patients, 2 in 8 patients, 3 in 18 patients, and 4 (RWA) in 24 patients. The duration between first and second staged operations was $4.8 \pm 4.0$ years and $5.8 \pm 7.3$ years between the second and third staged operations. Twenty-four patients reached RWA (5 patients in AAE group, 3 patients in AAAD group, 10 patients in TAAA group, and 6 patients in extensive aneurysm group) within $2.5 \pm 3.8$ years after initial repair.
Freedom from aortic-related events was $83.7 \pm 4.4 \%$ at 5 years and $63.7 \pm 6.8 \%$ at 10 years (Figure $4, B$ ). Outside of 7 patients requiring reoperation (all repairs related to previous repairs at our facility), 1 patient with deep wound infection, and 5 patients with late deaths, a total of 15 patients experienced an aortic-related event. One patient underwent aortic valve replacement for recurrent aortic regurgitation at an outside hospital. Four patients had AAAD and 4 patients had acute type B aortic dissection. Four patients underwent peripheral arterial aneurysm repair (infrarenal abdominal aorta, common iliac artery, 


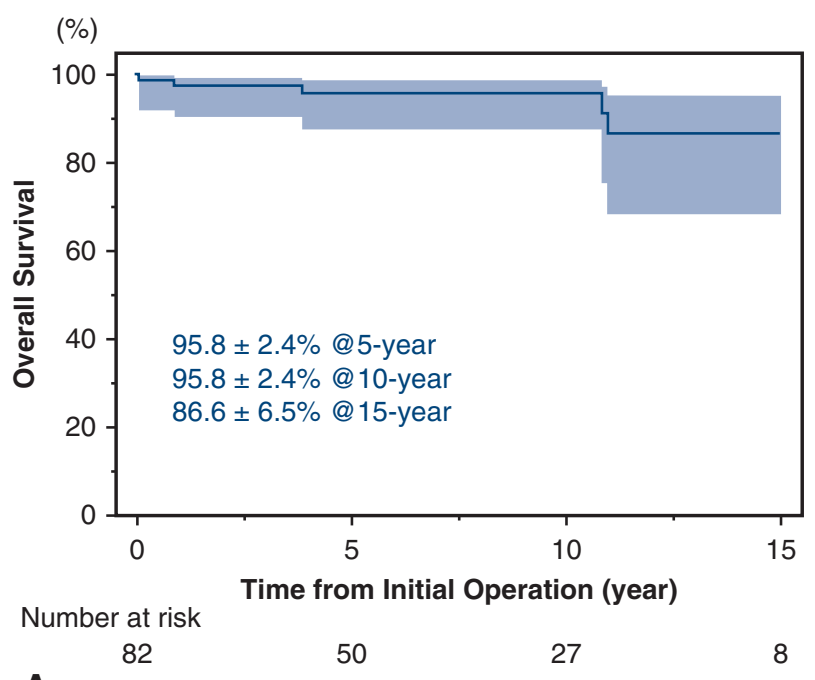

A

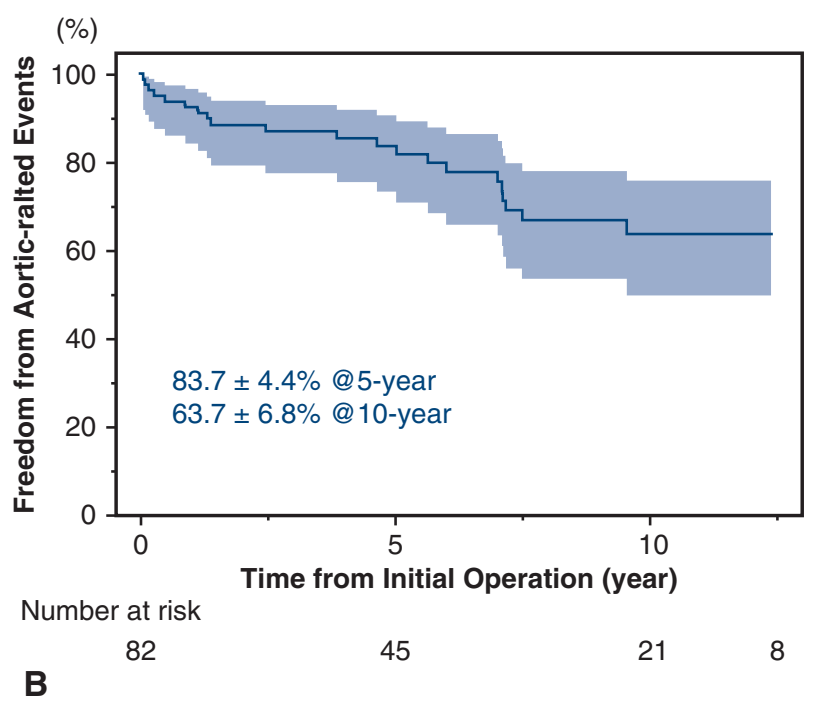

FIGURE 4. Kaplan-Meier curve for overall survival after the initial operation (A) and freedom from aortic-related event (B).

subclavian artery, and femoral artery). Two patients mentioned previously died of aneurysm rupture. Among those who achieved RWA, 6 patients required aortic reoperation. Three received ICA cuff aneurysm repair (Video 3 ) and 3 received peripheral artery aneurysm repair.

\section{DISCUSSION}

In this study, our staged aortic-replacement strategies were based on 2 factors: (1) aortic segments and (2) aortic pathologies (Figure 5). Twenty-four patients reached RWA, whereas 32 patients received only 1 segment repair. The reason for this variation is due to variation in rates of disease progression, as well as genetic heterogeneity across each patient. The presence or lack of aortic dissection also contributes to this variation. The concept of "total aortic care" should be adopted for patients who not only have developed disease but also have a single segment aortic lesion. Our strategies may apply for patients who have had previous aortic repair at other institutions.

In 1984, Crawford and colleagues ${ }^{13}$ reported 2 cases of 2-staged RWA, including 1 patient with MFS. Since then, few reports have described successful single-stage repair of the entire aorta. ${ }^{14}$ Recently, Hu and colleagues ${ }^{15}$ reported on 6 patients with 2-staged RWA (ie, root replacement and 1 -stage replacement from the ascending aorta to the aortic bifurcation), with no mortality at 14 months. Estrera and colleagues ${ }^{16}$ reported on 39 patients with staged-graft replacement from the ascending aorta to the aortic bifurcation, including 14 patients with connective tissue disorders. Although aortic root replacement was not performed in all patients, the study showed an acceptable mortality and morbidity rate (no early death and no stroke) and long-term survival $(57.7 \%$ and $30.0 \%$ at 10 and 20 years). RWA is considered to be one of the treatment goals for MFS with aortic disease. However, our study demonstrates that cuff aneurysm repair and peripheral artery aneurysm repair, as well as graft infection, may be emerging problems following RWA.

Valve-sparing procedures were developed in the 1990s. David $^{17}$ reported excellent long-term outcomes: freedom from reoperation was $94.9 \%$ and $87.6 \%$ at 10 years and 15 years after surgery, respectively. In our previous report, freedom from reoperation after valve-sparing reimplantation was $94.5 \%$ and $84.8 \%$ at 5 and 10 years in a cohort of 53 patients with MFS. ${ }^{18}$ Recent reports recommended surgical intervention on the aortic root when the largest diameter reaches $50 \mathrm{~mm}^{19,20}$; however, improvements in valve-sparing procedures may permit earlier surgical intervention for high-risk patients groups, such as young women. ${ }^{21}$

Late deaths after root replacement in patients with MFS still occur in approximately $47.4 \%$ of cases, secondary to cardiovascular causes. ${ }^{22}$ Therefore, patients with MFS typically require subsequent aortic repairs in the downstream aorta, particularly in the setting of aortic dissection. ${ }^{23}$ The guidelines advocate for surgical intervention when the downstream aortic diameter exceeds $50 \mathrm{~mm} .{ }^{24}$ In contrast, den Hartog and colleagues ${ }^{25}$ reported that none of the 54 patients in their study with type B aortic dissection reached this threshold. Bachet and colleagues ${ }^{26}$ also suggested that replacement of the aortic arch during elective aortic root replacement is unnecessary, even in patients with chronic distal residual dissection, because of low incidence of aortic arch growth.

Dissection both before and after root replacement has an important role in determining the need and strategy for additional surgery. In patients without dissection, freedom from reoperation was $92.0 \%, 86.0 \%$, and $64.0 \%$ at 5,10 , 


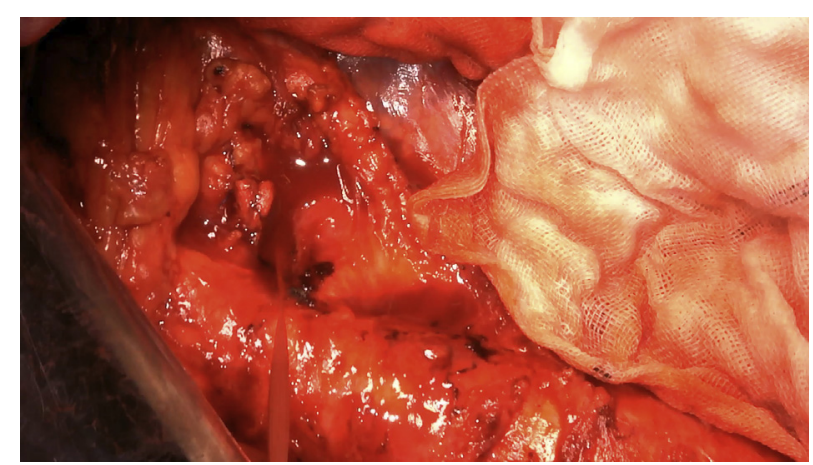

VIDEO 3. The patient underwent total arch-thoracoabdominal aortic repair via left thoracotomy as a first-stage operation, and valve-sparing root replacement reimplantation via median sternotomy as a second-stage operation (reaching replacement of the whole aorta). The patient experienced reoperation for cuff aneurysm of intercostal artery and visceral branch. Cuff aneurysm repair: The aneurysm was exposed via the fifth intercostal space with dividing costal arch under the right semirecumbent position. After establishing partial cardiopulmonary bypass (left femoral artery inflow and right femoral vein drainage), segmental replacement was performed in the order of 2 intercostal cuff aneurysms and visceral cuff aneurysm. Each vessel was interposed by the branched graft. Video available at: https://www.jtcvs.org/article/S0022-5223(18)32504-2/fulltext.

and 15 years, respectively, in comparison with $65.0 \%$, $42.0 \%$ and $16.0 \%$ at 5,10 , and 15 years, respectively, for patients with a primary or later dissection $(P<.001) .{ }^{27}$ Coselli and colleagues ${ }^{28}$ found in 123 patients with MFS with aortic dissection that time from dissection onset to TAAA repair was longer in patients with DeBakey I (median, 6.5 years) than in patients with DeBakey III (median 2.9, years, $P<.001$ ). In regard to TAAA repair, these data suggest that concomitant total arch replacement and elephant trunk insertion should be considered during aortic root replacement for patients with AAE and distal residual dissection. Frozen elephant trunk may decrease the threshold of total arch replacement for MFS. ${ }^{29}$

LeMaire and colleagues $^{30}$ reported that hospital mortality was $6 \%(2 / 31)$ in cases of descending thoracic repair and $3 \%(6 / 178)$ in cases of TAAA repair,

\section{Strategies for Staged-Aortic Repair in Patients with Marfan Symdrome}

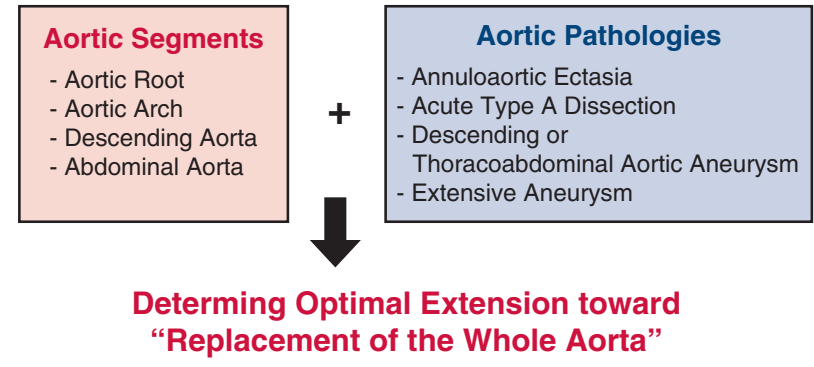

FIGURE 5. Strategies for staged-aortic replacement are based on 2 factors: (1) aortic segments and (2) aortic pathologies. respectively. Our previous report demonstrated good early (hospital mortality $0 \%$ ) and long-term results (freedom from reoperation at 8 years, $83.9 \%$ ) for graft replacement of TAAA, even for segments of the aorta for which surgery was not yet indicated. ${ }^{10}$ The low incidence of spinal cord injury was also supported our extended replacement strategy, particularly in low-risk patients because 1 patient required additional repair for residual abdominal aorta.

In patients with MFS with AAAD, total arch replacement is indicated. Rylski and colleagues ${ }^{31}$ reported that hemiarch replacement resulted in subsequent aortic arch reoperation (freedom from arch reoperation was $86.5 \%$ and $64.0 \%$ at 10 and 20 years, respectively). In terms of the aortic root, they also reported that freedom from aortic root reoperation in patients with a previous primary aortic root procedure was $95.0 \%, 88.0 \%$, and $79.0 \%$ at 5,10 , and 20 years. In patients who underwent a supra-coronary procedure, freedom from aortic root reoperation was $83.0 \%$, $60.0 \%$, and $20.0 \%$ at 5,10 , and 20 years. Although the AAAD (DeBakey type I) repair was performed as a emergent surgery, aortic root and total arch replacement with elephant trunk insertion was preferable in patients with stable hemodynamics. Even when both procedures could not be tolerated, either procedure alone provided several benefits for long-term outcomes, as well as a foundation for adequate planning for next stage operation.

The indication for nondissecting aortic arch replacement in patients with MFS remains controversial. Schoenhoff and colleagues $^{32}$ described that patients with MFS undergoing elective root repair had a low risk of reintervention of the aortic arch, suggesting primary arch replacement was likely unjustified. Tagusari and colleagues ${ }^{6}$ also reported that the incidence of new dissections in the residual intact arch after aortic root replacement, and, therefore, the need for subsequent total arch replacement, are extremely low $(3.8 \%)$. The actuarial freedom from operation of the aortic arch was $90.5 \%$ at 20 years. Although aortic arch repair was not indicated, 4 patients experienced AAAD in their intact aortic arch (diameter $<40 \mathrm{~mm}$ ), including 1 patient who underwent emergent AAAD repair at outside hospital Three of four patients had previous aortic root and TAAA replacement. Two patients were asymptomatic and were diagnosed incidentally follow-up visit. Although it is difficult to predict when patients with MFS will experience acute dissection, frequent imaging can be used to screen for the development of acute dissection.

The use of endovascular therapy for MFS remains controversial. The current consensus is that stent grafts should be used with great caution when repairing aortic dissections in patients with MFS or other connective tissue disorders. $^{33}$ Despite high rates of endoleaks and reintervention, endovascular repair may offer a viable option in patients who have contraindications to open 
surgery. ${ }^{34}$ In situations such as a bridging use in emergencies, endovascular aortic repair should be applied. $^{35}$ Roselli and colleagues ${ }^{5}$ also suggested the effectiveness of thoracic endovascular repair for late reintervention, typically following elephant trunk operation. Long-term evidence is required to apply these procedures for such a young and low-risk patient cohort.

Reoperation was indicated for 1 patient complicated deep wound infection (treated with continuous irrigation) and 3 patients with graft infection. For those with graft infection, first-line treatment consisted of debridement and in situ graft replacement. Continuous irrigation and meticulous assessment via positron emission tomography/computed tomography was used, given the life-long risk for reinfection in these patients. The cuff aneurysm following island technique was also an emerging problem, for which our surgical indication was $>50 \mathrm{~mm}$. To prevent cuff aneurysms in MFS, individual reconstruction was necessary.

Limitations of our study included its retrospective nature. Second, approximately one third of the patients in this study underwent aortic repair before entering our hospital. Regardless, these patients were included, as it is typical for patients with MFS undergo surgery without follow-up. Third, the diagnosis of MFS was defined using the current Ghent criteria as opposed to genetic analysis. However, the study demonstrated important clinical findings with respect to surgical strategies for aortic disease of MFS. Further analysis is needed.

\section{CONCLUSIONS}

Our strategies for staged replacement of the thoracic and thoracoabdominal aorta in MFS resulted in excellent early- and long-term outcomes. Furthermore, periodic follow-up post-RWA was required to prepare for subsequent aortic-related events.

\section{Conflict of Interest Statement}

Authors have nothing to disclose with regard to commercial support.

\section{References}

1. Murdoch JL, Walker BA, Halpern BL, Kuzma JW, McKusick VA. Life expectancy and causes of death in the Marfan syndrome. N Engl J Med. 1972; 286:804-8.

2. Silverman DI, Burton KJ, Gray J, Bosner MS, Kochoukos NT, Roman MJ, et al. Life expectancy in the Marfan syndrome. Am J Cardiol. 1995;75:157-60.

3. Finkbohner R, Johnston D, Crawford ES, Coselli J, Milewicz DM. Marfan syndrome long-term survival and complications after aortic aneurysm repair. Circulation. 1995;91:728-33.

4. Crawford ES, Coselli JS, Svensson LG, Safi HJ, Hess KR. Diffuse aneurysmal disease (chronic aortic dissection, Marfan, and mega aorta syndromes) and multiple aneurysm. Treatment by subtotal and total aortic replacement emphasizing the elephant trunk operation. Ann Surg. 1990;211:521.

5. Roselli EE, Idrees JJ, Lowry AM, Masabni K, Soltesz EG, Johnston DR, et al. Beyond the aortic root: staged open and endovascular repair of arch and descending aorta in patients with connective tissue disorders. Ann Thorac Surg. 2016;101:906-12.

6. Tagusari O, Ogino H, Kobayashi J, Bando K, Minatoya K, Sasaki H, et al. Should the transverse aortic arch be replaced simultaneously with aortic root replacement for annuloaortic ectasia in Marfan syndrome? J Thorac Cardiovasc Surg. 2004; $127: 1373-80$.

7. Loeys BL, Dietz HC, Braverman AC, Callewaert BL, De Backer J, Devereux RB, et al. The revised Ghent nosology for the Marfan syndrome. J Med Genet. 2010; 47:476-85.

8. Matsumori M, Tanaka H, Kawanishi Y, Onishi T, Nakagiri K, Yamashita T, et al. Comparison of distensibility of the aortic root and cusp motion after aortic root replacement with two reimplantation techniques: Valsalva graft versus tube graft. Interact Cardiovasc Thorac Surg. 2007;6:177-81.

9. Omura A, Miyahara S, Yamanaka K, Sakamoto T, Matsumori M, Okada K, et al. Early and late outcomes of repaired acute DeBakey type I aortic dissection after graft replacement. J Thorac Cardiovasc Surg. 2016;151: 341-8.

10. Omura A, Tanaka A, Miyahara S, Sakamoto T, Nomura Y, Inoue T, et al. Early and late results of graft replacement for dissecting aneurysm of thoracoabdominal aorta in patients with Marfan syndrome. Ann Thorac Surg. 2012;94:759-65.

11. Matsueda T, Ikeno Y, Yokawa K, Koda Y, Henmi S, Inoue T, et al. One-stage replacement of the aorta from arch to thoracoabdominal region. J Thorac Cardiovasc Surg. 2018;155:498-504.

12. Hino Y, Okada K, Oka T, Inoue T, Tanaka A, Omura A, et al. Extended replacement of the thoracic aorta. Eur J Cardiothorac Surg. 2013;43:176-81; discussion 181.

13. Crawford ES, Crawford JL, Stowe CL, Safi HJ. Total aortic replacement for chronic aortic dissection occurring in patients with and without Marfan's syndrome. Ann Surg. 1984;199:358.

14. Svensson LG, Shahian DM, Davis FG, Entrup MH, Kimmel WA, McGrath DM, et al. Replacement of entire aorta from aortic valve to bifurcation during one operation. Ann Thorac Surg. 1994;58:1164-6.

15. Hu XP, Chang Q, Zhu JM, Yu CT, Liu ZG, Sun LZ. One-stage total or subtotal aortic replacement. Ann Thorac Surg. 2006;82:542-6.

16. Estrera AL, Sandhu HK, Afifi RO, Nguyen TC, Charlton-Ouw KM, Azizzadeh A, et al. Early and late outcomes after complete aortic replacement. Ann Thorac Surg. 2015;100:528-34.

17. David TE. Aortic valve haemodynamics after aortic valve-sparing operations. Eur J Cardiothorac Surg. 2012;41:788-9.

18. Miyahara S, Okita Y. Overview of current surgical strategies for aortic disease in patients with Marfan syndrome. Surg Today. 2016;46:1006-18.

19. Elefteriades JA. Natural history of thoracic aortic aneurysms: indications for surgery, and surgical versus nonsurgical risks. Ann Thorac Surg. 2002;74:S1877-80; discussion S1892-8.

20. Judge DP, Dietz HC. Marfan's syndrome. Lancet. 2005;366:1965-76.

21. Hiratzka LF, Bakris GL, Beckman JA, Bersin RM, Carr VF, Casey DE Jr, et al. 2010 ACCF/AHA/AATS/ACR/ASA/SCA/SCAI/SIR/STS/SVM Guidelines for the diagnosis and management of patients with thoracic aortic disease. A Report of the American College of Cardiology Foundation/American Heart Association Task Force on Practice Guidelines, American Association for Thoracic Surgery, American College of Radiology, American Stroke Association, Society of Cardiovascular Anesthesiologists, Society for Cardiovascular Angiography and Interventions, Society of Interventional Radiology, Society of Thoracic Surgeons, and Society for Vascular Medicine. J Am Coll Cardiol. 2013;62: 1039-40.

22. Gott VL, Greene PS, Alejo DE, Cameron DE, Naftel DC, Miller DC, et al. Replacement of the aortic root in patients with Marfan's syndrome. $N$ Engl J Med. 1999;340:1307-13.

23. Tochii M, Hattori K, Ishikawa H, Ishida M, Higuchi Y, Amano K, et al. Mid-term outcomes of cardiovascular surgery for patients with Marfan syndrome. Gen Thorac Cardiovasc Surg. 2015;63:267-72.

24. Erbel R, Aboyans V, Boileau C, Bossone E, Bartolomeo RD, Eggebrecht H, et al. 2014 ESC Guidelines on the diagnosis and treatment of aortic diseases: document covering acute and chronic aortic diseases of the thoracic and abdominal aorta of the adult. The Task Force for the Diagnosis and Treatment of Aortic Diseases of the European Society of Cardiology (ESC). Eur Heart J. 2014;35: 2873-926.

25. den Hartog AW, Franken R, Zwinderman AH, Timmermans J, Sholte AJ, van den Berg MP, et al. The risk for type B aortic dissection in Marfan syndrome. J Am Coll Cardiol. 2015;65:246-54. 
26. Bachet J, Larrazet F, Goudot B, Dreyfus G, Folliguet T, Laborde F, et al. When should the aortic arch be replaced in Marfan patients? Ann Thorac Surg. 2007;83:774-9.

27. Schoenhoff FS, Jungi S, Czerny M, Roost E, Reineke D, Matyas G, et al. Acute aortic dissection determines the fate of initially untreated aortic segments in Marfan syndrome. Circulation. 2013;127:1569-75.

28. Coselli JS, Green SY, Price MD, Hash JA, Ouyang Y, Volguina IV, et al. Results of open surgical repair in patients with Marfan syndrome and distal aortic dissection. Ann Thorac Surg. 2016;101:2193-201.

29. Ma WG, Zhang W, Zhu JM, Ziganshin BA, Zhi AH, Zheng J, et al. Long-term outcomes of frozen elephant trunk for type A aortic dissection in patients with Marfan syndrome. J Thorac Cardiovasc Surg. 2017;154: 1175-89.

30. LeMaire SA, Carter SA, Volguina IV, Laux AT, Milewicz DM, Borsato GW, et al. Spectrum of aortic operations in 300 patients with confirmed or suspected Marfan syndrome. Ann Thorac Surg. 2006;81:2063-78.

31. Rylski B, Bavaria JE, Beyersdorf F, Branchetti E, Desai ND, Milewski RK, et al. Type A aortic dissection in Marfan syndrome: extent of initial surgery determines long-term outcome. Circulation. 2014;129:1381-6.
32. Schoenhoff FS, Kadner A, Czerny M, Jungi S, Meszaros K, Schmideli J, et al Should aortic arch replacement be performed during initial surgery for aortic root aneurysm in patients with Marfan syndrome? Eur J Cardiothorac Surg. 2013;44:346-51; discussion 351.

33. Lin PH, Huynh TT, Kougias P, Huh J, LeMaire SA, Coselli JS. Descending thoracic aortic dissection: evaluation and management in the era of endovascular technology. Vasc Endovasc Surg. 2009;43:5-24.

34. Marcheix B, Rousseau H, Bongard V, Heijmen RH, Nienaber CA, Ehrlich M, et al. Stent grafting of dissected descending aorta in patients with Marfan's syndrome: mid-term results. JACC Cardiovasc Interv. 2008;1:673-80.

35. Lombardi JV, Cambria RP, Nienaber CA, Chiesa R, Teebken O, Lee A, et al. Prospective multicenter clinical trial (STA- BLE) on the endovascular treatment of complicated type B aortic dissection using a composite device design. J Vasc Surg. 2012;55:629-40.

Key Words: Marfan syndrome, connective tissue disease, aortic surgery, aortic root replacement, aortic arch replacement, thoracoabdominal aortic repair 
TABLE E1. Details of previous aortic repair before first-stage operation

\begin{tabular}{|c|c|c|c|c|c|}
\hline Procedures & $\begin{array}{c}\text { Whole } \\
(n=38)\end{array}$ & $\begin{array}{c}\text { AAE } \\
(\mathbf{n}=\mathbf{1})\end{array}$ & $\begin{array}{l}\text { AAAD } \\
(\mathbf{n}=\mathbf{0})\end{array}$ & $\begin{array}{c}\text { Des/TAAA } \\
(\mathbf{n}=\mathbf{2})\end{array}$ & $\begin{array}{c}\text { Ex } \\
(n=1)\end{array}$ \\
\hline Aortic root replacement & 17 & 0 & 0 & 11 & 6 \\
\hline Hemiarch replacement & 3 & 1 & 0 & 2 & 0 \\
\hline Total arch replacement & 3 & 0 & 0 & 3 & 0 \\
\hline Root replacement + total arch replacement & 4 & 0 & 0 & 4 & 0 \\
\hline Descending aorta graft replacement & 8 & 2 & 1 & 4 & 1 \\
\hline TAAA repair & 1 & 0 & 0 & 0 & 1 \\
\hline TEVAR & 2 & 0 & 0 & 2 & 0 \\
\hline
\end{tabular}

$\overline{A A E}$, Annuoaortic ectasia; $A A A D$, acute type A aortic dissection; Des/TAAA, descending thoracic or thoracoabdominal aortic aneurysm; $E x$, extensive aneurysm; TAAA, thoracoabdominal aortic aneurysm; TEVAR, thoracic endovascular aneurysm repair.

TABLE E2. Operative indications and procedures in first-stage operation

\begin{tabular}{|c|c|c|c|c|c|}
\hline Procedures & $\begin{array}{c}\text { Whole } \\
(n=82)\end{array}$ & $\begin{array}{c}\text { AAE } \\
(\mathbf{n}=39)\end{array}$ & $\begin{array}{c}\text { AAAD } \\
(n=14)\end{array}$ & $\begin{array}{c}\text { Des/TAAA } \\
(\mathbf{n}=\mathbf{2 2})\end{array}$ & $\begin{array}{c}\mathbf{E x} \\
(\mathbf{n}=7)\end{array}$ \\
\hline Root replacement & $36(44)$ & 32 & 4 & 0 & 0 \\
\hline Valve-sparing reimplantation & $33(40)$ & 30 & 3 & 0 & 0 \\
\hline Total arch replacement & $7(8.5)$ & 0 & 4 & 0 & 2 \\
\hline Root replacement + total arch replacement & $13(16)$ & 7 & 6 & 0 & 0 \\
\hline Reimplantation + total arch replacement & $11(13)$ & 5 & 6 & 0 & 0 \\
\hline Descending aorta graft replacement & $1(1.2)$ & 0 & 0 & 1 & 0 \\
\hline TAAA repair & $21(26)$ & 0 & 0 & 21 & 0 \\
\hline Extent I & $0(0)$ & 0 & 0 & 0 & 0 \\
\hline Extent II & $16(20)$ & 0 & 0 & 16 & 0 \\
\hline Extent III & $5(6.1)$ & 0 & 0 & 5 & 0 \\
\hline Extent IV & $0(0)$ & 0 & 0 & 0 & 0 \\
\hline Total arch-descending aorta graft replacement & $1(1.2)$ & 0 & 0 & 0 & 1 \\
\hline Total arch-TAAA graft replacement & $3(3.7)$ & 0 & 0 & 0 & 3 \\
\hline
\end{tabular}

$A A E$, Annuoaortic ectasia; $A A A D$, acute type A aortic dissection; Des/TAAA, descending thoracic or thoracoabdominal aortic aneurysm; $E x$, extensive aneurysm; TAAA, thoracoabdominal aortic aneurysm. 
TABLE E3. Operative indications and procedures in second-stage operation

\begin{tabular}{|c|c|c|c|c|c|}
\hline Procedures & $\begin{array}{c}\text { Whole } \\
(n=25)\end{array}$ & $\begin{array}{c}\text { AAE } \\
(\mathbf{n}=\mathbf{5}) \\
\end{array}$ & $\begin{array}{l}\text { AAAD } \\
(\mathbf{n}=\mathbf{3}) \\
\end{array}$ & $\begin{array}{c}\text { Des/TAAA } \\
(n=16)\end{array}$ & $\begin{array}{c}\mathbf{E x} \\
(\mathbf{n}=\mathbf{1})\end{array}$ \\
\hline Root replacement & $5(20)$ & 5 & 0 & 0 & 0 \\
\hline Valve-sparing reimplantation & $4(16)$ & 4 & 0 & 0 & 0 \\
\hline Total arch replacement & $3(12)$ & 0 & 3 & 0 & 0 \\
\hline Root replacement + total arch replacement & $0(0)$ & 0 & 0 & 0 & 0 \\
\hline Reimplantation + total arch replacement & $0(0)$ & 0 & 0 & 0 & 0 \\
\hline Descending aorta graft replacement & $2(8.0)$ & 0 & 0 & 2 & 0 \\
\hline TAAA & $14(56)$ & 0 & 0 & 14 & 0 \\
\hline Extent I & $0(0)$ & 0 & 0 & 0 & 0 \\
\hline Extent II & $11(44)$ & 0 & 0 & 11 & 0 \\
\hline Extent III & $3(12)$ & 0 & 0 & 3 & 0 \\
\hline Extent IV & $0(0)$ & 0 & 0 & 0 & 0 \\
\hline Total arch-descending aorta graft replacement & $1(4.0)$ & 0 & 0 & 0 & 1 \\
\hline Total arch-TAAA graft replacement & $0(0)$ & 0 & 0 & 0 & 0 \\
\hline
\end{tabular}

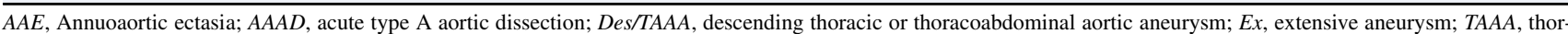
acoabdominal aortic aneurysm.

TABLE E4. Operative indications and procedures in third-stage operation

\begin{tabular}{|c|c|c|c|c|c|}
\hline Procedures & $\begin{array}{l}\text { Whole } \\
(n=4)\end{array}$ & $\begin{array}{c}\mathbf{A A E} \\
(\mathbf{n}=\mathbf{1})\end{array}$ & $\begin{array}{l}\text { AAAD } \\
(\mathbf{n}=\mathbf{0})\end{array}$ & $\begin{array}{c}\text { Des/TAAA } \\
(\mathbf{n}=\mathbf{2})\end{array}$ & $\begin{array}{c}\mathbf{E x} \\
(\mathbf{n}=\mathbf{1})\end{array}$ \\
\hline Root replacement & $1(25)$ & 1 & 0 & 0 & 0 \\
\hline Valve-sparing reimplantation & $1(25)$ & 1 & 0 & 0 & 0 \\
\hline Total arch replacement & $1(25)$ & 0 & 0 & 0 & 1 \\
\hline Root replacement + total arch replacement & $0(0)$ & 0 & 0 & 0 & 0 \\
\hline Reimplantation + total arch replacement & $0(0)$ & 0 & 0 & 0 & 0 \\
\hline Descending aorta graft replacement & $1(25)$ & 0 & 0 & 1 & 0 \\
\hline TAAA & $1(25)$ & 0 & 0 & 0 & 0 \\
\hline Extent I & $0(0)$ & 0 & 0 & 0 & 0 \\
\hline Extent II & $0(0)$ & 0 & 0 & 0 & 0 \\
\hline Extent III & $1(25)$ & 0 & 0 & 1 & 0 \\
\hline Extent IV & $0(0)$ & 0 & 0 & 0 & 0 \\
\hline Total arch-descending aorta graft replacement & $0(0)$ & 0 & 0 & 0 & 0 \\
\hline Total arch-TAAA graft replacement & $0(0)$ & 0 & 0 & 0 & 0 \\
\hline
\end{tabular}

$A A E$, Annuoaortic ectasia; $A A A D$, acute type A aortic dissection; Des/TAAA, descending thoracic or thoracoabdominal aortic aneurysm; $E x$, extensive aneurysm; TAAA, thoracoabdominal aortic aneurysm. 